\title{
Aberrant Adiposity and Ectopic Lipid Deposition Characterize the Adult Phenotype of the Preterm Infant
}

\author{
E. LOUISE THOMAS, JAMES R. PARKINSON, MATTHEW J. HYDE, IVAN K.S. YAP, ELAINE HOLMES, CAROLINE J. DORÉ, \\ JIMMY D. BELL, AND NEENA MODI
}

\begin{abstract}
Metabolic and Molecular Imaging Group [E.L.T., J.D.B.], Imperial College London, London W12 ONN, United Kingdom; Department of Medicine [J.R.P., M.J.H., N.M.], Imperial College London, London SW10 9NH, United Kingdom; Department of Surgery and Cancer [I.K.S.Y., E.H.], Imperial College London, London SW7 2AZ, United Kingdom; Clinical Trials Unit [C.D.], Medical Research Council, London NW1 2DA, United Kingdom
\end{abstract}

\begin{abstract}
Our investigation addresses the hypothesis that disruption of third trimester development by preterm birth alters multiple biological pathways affecting metabolic health in adult life. We compared healthy adult volunteers aged $18-27$ y born at $\leq 33$ wk gestation or at term. We used whole-body MRI, ${ }^{1} \mathrm{H}$ magnetic resonance spectroscopy (MRS) of liver and muscle, metabonomic profiling of blood and urine, and anthropometric and blood pressure measurements. Preterm subjects had greater (mean difference $(95 \%$ CI)) total $[2.21 \mathrm{~L}(0.3,4.1), p=0.03]$ and abdominal adipose tissue [internal $0.51(0.1,0.9), p=0.007$ ]; blood pressure [systolic $6.5 \mathrm{~mm}$ $\mathrm{Hg}(2.2,10.8), p=0.004$; diastolic 5.9 (1.8, 10.1), $p=0.006]$; and ectopic lipid (ratio $(95 \% \mathrm{CI})$ ), intrahepatocellular lipid (IHCL) 3.01 $(1.78,5.28) p<0.001$, and tibialis-intramyocellular lipid (T-IMCL) $[1.31(1.02,1.69) p=0.04]$. In preterm, compared with term men, there was greater internal adipose tissue [mean (SD); men: preterm 4.0 (1.6), term 2.7 (1.1) liters; women: preterm 2.6 (0.9); term 2.6 $(0.5)$; gender-gestation interaction $p=0.048$ ] and significant differences in the urinary metabolome (elevated methylamines and acetylglycoproteins, lower hippurate). We have identified multiple premorbid biomarkers in ex-preterm young adults, which are most marked in men and indicative of risks to later wellbeing. These data offer insight into biological trajectories affected by preterm birth and/or neonatal care. (Pediatr Res 70: 507-512, 2011)
\end{abstract}

A round $2 \%$ of births in the developed world are below 33 wk gestation. This rate is rising as is survival and $>90 \%$ of these infants will go home. Survival free of major impairment is also rising, bringing with it the expectation of life-long health. Preterm birth may be a risk to adult health $(1,2)$. Several groups describe higher blood pressure (3-7). Insulin resistance (8) and poorer reproductive health (9) have also been reported. The biological mediators are unknown.

We have previously shown that by term, preterm infants have an altered body composition with significantly greater abdominal adipose tissue (10) and intrahepatocellular lipid (IHCL) (11). There is a high degree of correlation between hypertension, insulin resistance, and abdominal obesity. Abdominal adipose tissue in particular seems to play a major role

Received March 2, 2011; accepted May 9, 2011.

Correspondence: Neena Modi, M.D., Section of Neonatal Medicine, Department of Medicine, Chelsea and Westminster campus, Imperial College London, 369 Fulham Road, London SW10 9NH, United Kingdom; e-mail: n.modi@imperial.ac.uk

Supported by the Medical Research Council and Chelsea and Westminster N.H.S Foundation Trust.

The authors report no conflicts of interest. in the pathogenesis of the metabolic syndrome (12). Increased "ectopic" lipid in liver and muscle as IHCL and soleus and tibialis intramyocellular lipid (S-IMCL and T-IMCL) are also strongly associated with these conditions (13).

In this proof-of-concept study, we postulated that disruption of the normal pattern of third trimester development by preterm birth will affect a range of systems affecting metabolic health. We tested the primary hypothesis that young adults born at or below 33 wk gestation would have increased abdominal adiposity in the absence of overt obesity. We also evaluated IHCL, IMCL, fasting glucose and insulin, insulin resistance, serum lipids and serum, and urine metabolomes.

\section{METHODS}

Approval for the study was obtained from the National Research Ethics Service (Charing Cross Hospital Research Ethics Committee). Written informed consent was obtained from all subjects. We recruited healthy young male and female volunteers aged $18-27 \mathrm{y}$, born at term or preterm $(\leq 33 \mathrm{wk}$ gestation) through advertisements in newsletters and websites and with the help of Bliss, a national UK premature baby charity. Before recruitment, a screening questionnaire was completed to exclude subjects with a history of smoking, dyslipidemia, or excess alcohol intake, and in women, any possibility of pregnancy. Sedentary subjects (either term or ex-preterm) were also excluded after physical activity classification (14).

Blood and urine samples were obtained after an overnight fast. Body mass $(\mathrm{kg})$, height $(\mathrm{cm})$, waist circumference $(\mathrm{WC})(\mathrm{cm})$, and hip circumference $(\mathrm{cm})$ were measured, and BMI $\left(\mathrm{kg} / \mathrm{m}^{2}\right)$ and waist-to-hip ratio (WHR) were calculated. Fasting glucose, total cholesterol, triglycerides, high density lipoprotein (HDL), low density lipoprotein (LDL), and insulin were measured by standard methods. Insulin sensitivity was assessed from concentrations of glucose and insulin using the Homeostasis Model Assessment of Insulin Resistance (15) and Quantitative Insulin Sensitivity Check Index (16).

Intramyocellular and intrahepatocellular lipid. Hepatic spectra were obtained using a PRESS sequence (TR $1500 \mathrm{~ms}$, TE $135 \mathrm{~ms}$ ) and IHCL determined relative to liver water content (17). Muscle spectra were obtained from the soleus (S-IMCL) and tibialis (T-IMCL) (TR 1500ms, TE 135ms, 256 averages). IMCL was determined relative to total muscle creatine signal after correcting for $\mathrm{T}_{1}$ and $\mathrm{T}_{2}$ (18).

Adipose tissue content and distribution. Whole-body magnetic resonance imaging (1.5T Achieva scanner; Phillips Medical Systems, Best, The Netherlands) was used to determine total and regional adipose tissue content as previously described (17). The s.c. and internal adipose tissue was quantified in liters as either abdominal or nonabdominal compartments. Total adipose tissue was calculated as the sum of these four compartments. Adipose tissue images were analyzed independently of the investigators, blind to subject and group identity by VardisGroup, (London, United Kingdom, Available at:

Abbreviations: IHCL, intrahepatocellular lipid; IMCL, intramyocellular lipid; S-IMCL, soleus-intramyocellular lipid; T-IMCL, tibialis-intramyocellular lipid 
www.vardisgroup.com) using an image segmentation program (sliceOmatic, Tomovision, Montreal, Canada).

High resolution ${ }^{1} \mathrm{H} N M R$ spectroscopic analyses. Proton nuclear magnetic resonance ( ${ }^{1} \mathrm{H}$ NMR) spectroscopy on blood and urine was performed at $300 \mathrm{~K}$ on a Bruker LC-NMR $600 \mathrm{MHz}$ spectrometer (Bruker Biospin, Karlsruhe, Germany) using standard sample preparation, parameters, and preprocessing algorithms (19). Spectra were automatically phased; baseline corrected, and referenced using an in-house routine written in MATLAB (The MathWorks, Natick, MA). Orthogonal projection to latent structure discriminant analysis (O-PLS-DA) (20) was used to optimally model class differences and to systematically identify metabolites contributing to the differences between preterm and term groups. The statistical significance and validity of the O-PLS-DA results were calculated using a permutation test (number of permutations $=10,000)(21)$. Group comparisons were calculated for preterm versus term (men and women combined) and individually for the male and the female subgroups (preterm versus term).

Data analyses. We used multiple linear regression (Stata Release 10.1) to examine group (preterm-term) and gender (men-women) differences and gender-group interaction. Adipose tissue volumes, ectopic lipid, blood pressure, and blood biochemistry were adjusted for BMI. The mean difference $(95 \% \mathrm{CI})$ was calculated for group and gender if the gendergroup interaction was nonsignificant (at the 5\% level). IHCL, S-IMCL, and T-IMCL are presented as the geometric mean and ratio (95\% CI) with analyses performed following $\log _{\mathrm{e}}$ transformation due to the skewed distribution of these data. Unless otherwise stated, other values are mean difference $(95 \% \mathrm{CI})$.

\section{RESULTS}

We recruited 48 volunteers, 23 born preterm (13 men and 10 women) at a mean gestational age of $29 \mathrm{wk}$ (range, 24 to 33 ) and mean birth weight of $1.366 \mathrm{~kg}$ (range, 0.650 to 2.10), and 25 born at full term (10 men and 15 women). Preterm and term subjects did not differ in any adult anthropometric parameter including BMI. Men had a significantly greater weight, height, BMI, WC, and waist-hip ratio compared with women. There was no evidence of a group-gender interaction in any baseline parameter (Table 1).

Adipose tissue volumes and ectopic lipid are shown in Table 2. The preterm group had significantly more total adipose tissue [mean difference $(95 \% \mathrm{CI}), 2.21 \mathrm{~L}$ ( 0.3 to 4.1 $\mathrm{L}), p=0.03]$. This was due to an increase in abdominal [s.c. $0.70 \mathrm{~L}(0.13$ to $1.27 \mathrm{~L}) p=0.02$; internal $0.51 \mathrm{~L}(0.1$ to $0.9 \mathrm{~L}), p=0.007$ ] and not nonabdominal adipose tissue. Overall, women had significantly greater total and s.c. (abdominal and nonabdominal) adipose tissue compared with men (all $p<0.001$ ), but there was evidence of gender specificity in adipose tissue partitioning in the preterm group. The increase in internal adipose tissue appeared only to affect preterm men [mean (SD); men: preterm 4.0 (1.6), term 2.7 (1.1); women: preterm $2.6(0.9)$; term $2.6(0.5)$; gender-gestation interaction $p=0.048]$. This was due to a difference in the internal abdominal compartment [mean (SD), men: preterm 2.1 (1.1), term 1.2 (0.6); women: preterm $1.1(0.6)$, term $1.1(0.3)$; gender-group interaction $p=0.056]$. Ectopic lipid was significantly elevated in the preterm subjects [IHCL ratio: 3.07 (95\% CI 1.78 to 5.28), $p<0.001$; T-IMCL: 1.31 (1.02 to 1.69$), p=0.04$ ]. There was no significant difference in S-IMCL $(p=0.9)$ nor any evidence of gender-group interaction in relation to ectopic lipid deposition.

Blood pressure (Table 3) was higher in the preterm group [mean difference $(95 \% \mathrm{CI})$, systolic $6.5 \mathrm{~mm} \mathrm{Hg}$ (2.2 to $10.8), p=0.004$; diastolic $5.9 \mathrm{~mm} \mathrm{Hg}$ (1.8 to 10.1$), p=$ 0.006]. There were no significant differences in blood

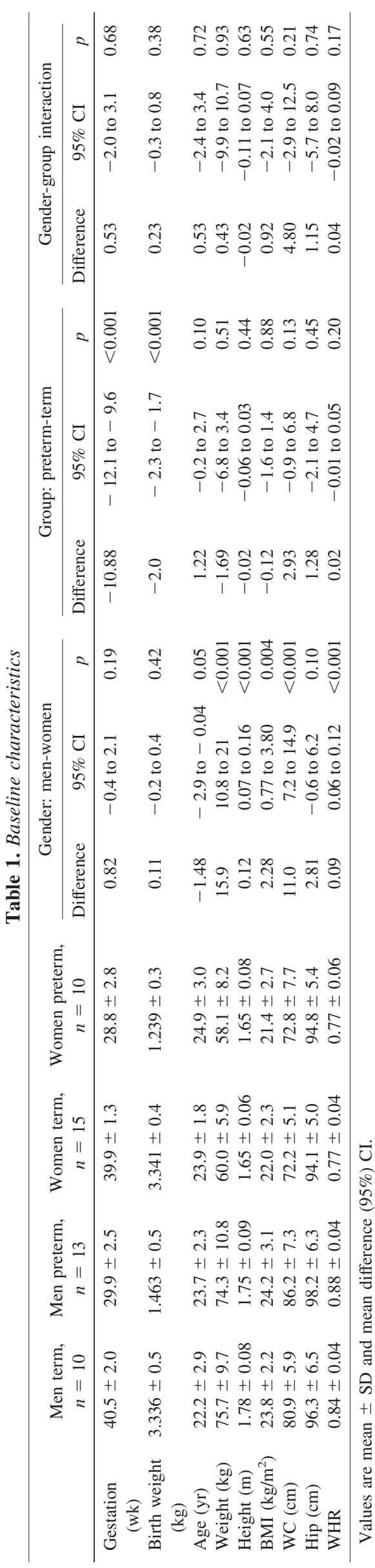



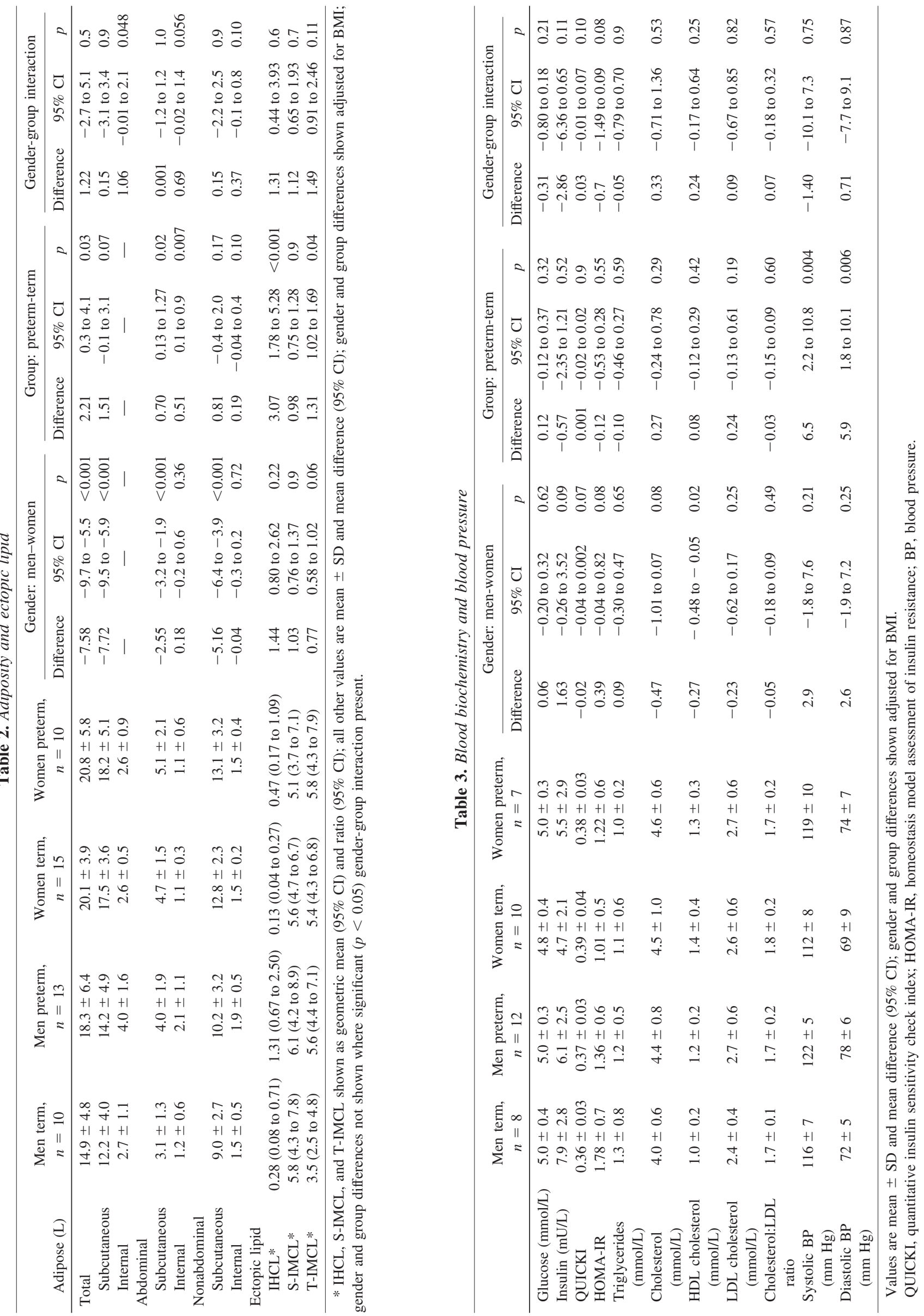
Table 4. Gender-specific differences in the urine metabolome of healthy young adults born $\leq 33$ wk gestation compared with term controls

\begin{tabular}{lccccc}
\hline \multicolumn{1}{c}{ Metabolite } & $\begin{array}{c}\text { Direction } \\
\text { of change }\end{array}$ & $\begin{array}{c}\text { Chemical } \\
\text { shift } \\
(\mathrm{ppm})\end{array}$ & Multiplicity & $\begin{array}{c}\text { Chemical } \\
\text { shift } \\
(\mathrm{ppm})\end{array}$ \\
\hline $\begin{array}{l}\text { Male preterm } \\
\text { Bile acids }\end{array}$ & + & $0.83-0.85$ & $\mathrm{~m}$ & 0.0004 \\
$\begin{array}{l}\text { 3-hydroxyisobutyrate } \\
\text { O-acetyl fragments }\end{array}$ & + & 1.36 & $\mathrm{~s}$ & 0.014 \\
$\quad$ of glycoproteins & + & 2.066 & $\mathrm{~s}$ & 0.012 \\
$\begin{array}{l}\text { Dimethylamine } \\
\text { Trimethylamine }\end{array}$ & - & 2.71 & $\mathrm{~s}$ & 0.030 \\
Taurine & + & 2.86 & $\mathrm{~s}$ & 0.009 \\
$\quad \begin{array}{l}\text { Guanidoacetate } \\
\text { Transaconitate }\end{array}$ & + & 3.42 & $\mathrm{t}$ & 0.030 \\
$\quad$ Hippurate & - & 3.8 & $\mathrm{~s}$ & 0.017 \\
Female preterm & - & 7.61 & $\mathrm{~s}$ & 0.003 \\
$\quad \begin{array}{l}\alpha \text {-ketoisovalerate } \\
N \text {-acetyl fragments }\end{array}$ & + & 1.145 & $\mathrm{~d}$ & 0.003 \\
$\quad$ of glycoproteins & + & 2.04 & $\mathrm{~d}$ & 0.030 \\
$\quad$ Trimethylamine & + & 2.86 & $\mathrm{~s}$ & 0.007 \\
\hline
\end{tabular}

+ , increase; - , decrease; multiplicities: $\mathrm{s}$, singlet; $\mathrm{d}$, doublet; $\mathrm{t}$, triplet; $\mathrm{m}$, multiplet; male: term, $n=7$; preterm $n=12$ and female: term, $n=10$; preterm, $n=7$.
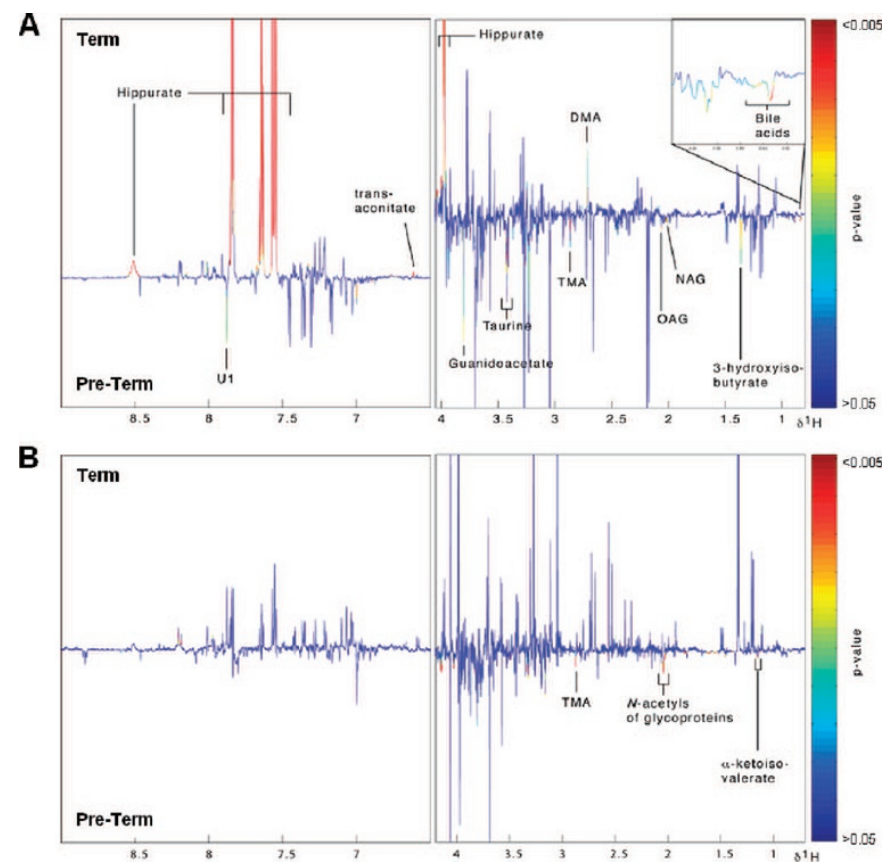

Figure 1. Coefficient plots derived from urinary ${ }^{1} \mathrm{H}$ NMR spectra in term and preterm young adults. (A) male $\left(Q^{2}: 31.5 \%, R^{2}: 35.0 \%\right)(B)$ female $\left(Q^{2}: 23.1 \%\right.$, $\left.R^{2}: 28.9 \%\right)$. The significance of each metabolite from the permutation test is interpreted using the covariance plot, where the colors projected onto the spectrum indicate the significance of the metabolites (blue indicating no significant difference at $p>0.05$ and red indicating a significant difference at $p<0.005$ ). The direction and magnitude of the signals relate to the covariation of the metabolites with the classes in the model. Group comparisons were calculated for the groups, preterm $v s$ term, individually for male and female subgroups. NAG, $\mathrm{N}$-acetyl fragments of glycoproteins; OAG, $O$-acetyl fragments of glycoproteins; DMA, dimethylamine; TMA, trimethylamine; U1, unknown metabolite 1 female: term $n=10$, preterm $n=7$; male: term $n=7$, preterm $n=12$.

biochemistry or insulin sensitivity. Urinary metabolite profiles revealed differences between term and preterm subjects more marked in the men (Table 4 and Fig. 1). Trimethylamine and acetylated glycoprotein were higher in preterm subjects. Preterm men had lower hippurate, taurine, dimethylamine, and transaconitate and higher 3-hydroxyisobutyrate, bile acids, and guanidinoacetate. No significant differences were detected between the serum metabolome of either men or women.

\section{DISCUSSION}

Using diverse techniques to interrogate a range of biological systems, we have revealed significant differences between adults born preterm and at term that merit further exploration. Although not different from term-born counterparts in external physique, our small group of preterm, healthy subjects had significantly increased whole-body adiposity, altered adipose tissue partitioning, higher systolic and diastolic blood pressure, increased IHCL and IMCL, and differences in the urinary metabolome. Although overall women had significantly greater total and s.c. adipose tissue than men, our data raise the possibility of greater vulnerability of preterm men to accumulate excess internal adipose tissue, especially in the abdominal compartment. Higher blood pressure in preterm subjects has been previously reported by several groups; the other findings are novel.

The anthropometric, adiposity, ectopic lipid, and blood pressure measurements in our term-born subjects were within the expected range for this age group. The increase in total adiposity in the preterm group was the consequence of an increase in the abdominal compartments. Increased abdominal adiposity and ectopic lipid accumulation in liver and muscle are associated with adverse metabolic health, type-2 diabetes, dyslipidemia, and hypertension (22-24). We found a striking 3-fold-higher IHCL content in preterm adults and significantly greater IMCL in the tibialis but not soleus muscle. Several studies indicate that IMCL is a good predictor of peripheral insulin resistance, although it is unclear whether S-IMCL or T-IMCL is of principal relevance $(25,26)$. These uncertainties notwithstanding, the preterm adult phenotype we have characterized is likely to become more pronounced with ageing, particularly in an obesogenic environment, and is predictive of risk to metabolic health.

We found no differences in plasma insulin, glucose, lipids, or indices of insulin sensitivity. This was unsurprising because our study lacked power to detect differences in young, healthy people. However, despite the small sample size, differences in urinary metabolites were found between term and preterm young adults that, analogous to the altered adiposity, were more pronounced in men. Both preterm men and women showed higher urinary acetylated glycoprotein fragments, metabolites associated with inflammation, a prime candidate cause of hypertension. This increase may be related to the elevated ectopic and central adiposity observed in our preterm subjects, because lipid overload associated with obesity is thought to induce cellular stress that initiates and perpetuates an inflammatory cycle (27). Higher blood pressure and lower hippurate in preterm men, with a similar trend in women, is in accord with large population studies showing a similar, inverse association between hippurate and blood pressure (28), a relationship 
that has been postulated to reflect the interactions between diet and gut microbial activity $(29,30)$, because hippurate is predominantly generated from the conjugation of benzoic acid with glycine. Urinary hippurate has also been shown to be inversely correlated with weight in humans and laboratory animals (31). Furthermore, the modulation of choline degradation products, dimethylamine and trimethylamine, also implicate gut microbial involvement in the differential signature of the term and preterm group. Although the clinical implications of the differences in urinary metabolite profile remain to be elucidated, our data indicate a role for metabonomic technologies in the identification of biomarkers for follow-up of preterm infants.

Our observations of aberrant adiposity and ectopic lipid deposition in young adults mirror the findings we have previously reported in preterm infants at term equivalent age (10). The elevated urinary bile acids we have noted in preterm men is in accord with a study examining the serum of preterm neonates (32). These cross-sectional data suggest that alterations arising in early infancy persist into adult life.

The strength of our study is that using diverse techniques to interrogate different biological systems, we have identified premorbid markers indicative of disruption of multiple metabolic pathways. Establishing the physiological basis for early life determinants of increased metabolic risk is complicated by the interaction between preterm birth and growth restriction, each of which contributes to the spectrum of outcomes associated with low birth weight. The indices we have used are potential biomarkers, opening the door to research to unravel these interactions and in due course attenuate damaging trajectories, without dependence on long-term follow-up to assess outcomes.

A further challenge is to identify the neonatal care practices that might be contributing to adverse long-term health or that might be used in prevention. Growth velocity in infancy is a key determinant of body size, adipose tissue mass, and body composition, irrespective of birth weight (33). Therefore, nutrition represents a potentially powerful tool for clinical intervention in both term and preterm populations.

Our study is small and requires replication with power to address multiple outcomes and control for confounders. This is potentially of great importance to the growing number of healthy ex-preterm adults because metabolic and cardiovascular screening is usually reserved for people who are overweight or much older, and a range of life-style and pharmacological interventions exist to attenuate progression to overt morbidity. Despite the limitations of our study, the data we present add to growing justification to monitor the health of preterm men and women beyond infancy and childhood.

Acknowledgments. We thank Giuliana Durighel and Julie Fitzpatrick (Imaging Sciences Department, Imperial College London) for technical assistance. We thank Stanislas Morin and John McCarthy (Imaging Sciences Department, Imperial College London), Sabita Uthaya (Neonatal Medi- cine, Imperial College), Olaf Beckonert (Biomolecular Medicine, Imperial College), and Bliss, the UK premature baby charity, for practical help.

\section{REFERENCES}

1. Stevenson CJ, West CR, Pharoah PO 2001 Dermatoglyphic patterns, very low birth weight, and blood pressure in adolescence. Arch Dis Child Fetal Neonatal Ed 84:F18-F22

2. Irving RJ, Belton NR, Elton RA, Walker BR 2000 Adult cardiovascular risk factors in premature babies. Lancet 355:2135-2136

3. Kistner A, Celsi G, Vanpee M, Jacobson SH 2005 Increased systolic daily ambulatory blood pressure in adult women born preterm. Pediatr Nephrol 20:232-233

4. Doyle LW, Faber B, Callanan C, Morley R 2003 Blood pressure in late adolescence and very low birth weight. Pediatrics 111:252-257

5. Hack M, Schluchter M, Cartar L, Rahman M 2005 Blood pressure among very low birth weight $(<1.5 \mathrm{~kg})$ young adults. Pediatr Res 58:677-684

6. Johansson S, Iliadou A, Bergvall N, Tuvemo T, Norman M, Cnattingius S 2005 Risk of high blood pressure among young men increases with the degree of immaturity at birth. Circulation 112:3430-3436

7. Keijzer-Veen MG, Finken MJ, Nauta J, Dekker FW, Hille ET, Frolich M, Wit JM, van der Heijden AJ 2005 Is blood pressure increased 19 years after intrauterine growth restriction and preterm birth? A prospective follow-up study in The Netherlands. Pediatrics 116:725-731

8. Hovi P, Andersson S, Eriksson JG, Jarvenpaa AL, Strang-Karlsson S, Makitie O, Kajantie E 2007 Glucose regulation in young adults with very low birth weight. N Engl J Med 356:2053-2063

9. Swamy GK, Ostbye T, Skjaerven R 2008 Association of preterm birth with long-term survival, reproduction, and next-generation preterm birth. JAMA 299:1429-1436

10. Uthaya S, Thomas EL, Hamilton G, Dore CJ, Bell J, Modi N 2005 Altered adiposity after extremely preterm birth. Pediatr Res 57:211-215

11. Thomas EL, Uthaya S, Vasu V, McCarthy JP, McEwan P, Hamilton G, Bell JD, Modi N 2008 Neonatal intrahepatocellular lipid. Arch Dis Child Fetal Neonatal Ed 93:F382-F383

12. Després JP, Lemieux I 2006 Abdominal obesity and metabolic syndrome. Nature 444:881-887

13. Consitt LA, Bell JA, Houmard JA 2009 Intramuscular lipid metabolism, insulin action, and obesity. IUBMB Life 61:47-55

14. Hagströmer M, Bergman P, De Bourdeaudhuij I, Ortega FB, Ruiz JR, Manios Y, Rey-López JP, Phillipp K, Sjöström M HELENA Study Group 2008 Concurrent validity of a modified version of the International Physical Activity Questionnaire (IPAQ-A) in European adolescents: the HELENA Study. Int J Obes (Lond) 32:S42S48

15. Matthews DR, Hosker JP, Rudenski AS, Naylor BA, Treacher DF, Turner RC 1985 Homeostasis model assessment: insulin resistance and beta-cell function from fasting plasma glucose and insulin concentrations in man. Diabetologia 28:412-419

16. Katz A, Nambi SS, Mather K, Baron AD, Follmann DA, Sullivan G, Quon MJ 2000 Quantitative insulin sensitivity check index: a simple, accurate method for assessing insulin sensitivity in humans. J Clin Endocrinol Metab 85:2402-2410

17. Thomas EL, Hamilton G, Patel N, O'Dwyer R, Doré CJ, Goldin RD, Bell JD, Taylor-Robinson SD 2005 Hepatic triglyceride content and its relation to body adiposity: a magnetic resonance imaging and proton magnetic resonance spectroscopy study. Gut $54: 122-127$

18. Rico-Sanz J, Thomas EL, Jenkinson G, Mierisova S, Iles R, Bell JD 1999 Diversity in levels of intracellular total creatine and triglycerides in human skeletal muscles observed by (1)H-MRS. J Appl Physiol 87:2068-2072

19. Beckonert O, Keun HC, Ebbels TM, Bundy J, Holmes E, Lindon JC, Nicholson JK 2007 Metabolic profiling, metabolomic and metabonomic procedures for NMR spectroscopy of urine, plasma, serum and tissue extracts. Nat Protoc 2:2692-2703

20. Cloarec O, Dumas ME, Trygg J, Craig A, Barton RH, Lindon JC, Nicholson JK, Holmes E 2005 Evaluation of the orthogonal projection on latent structure model limitations caused by chemical shift variability and improved visualization of biomarker changes in $1 \mathrm{H}$ NMR spectroscopic metabonomic studies. Anal Chem 77:517-526

21. Neuhäuser M, Manly BF 2004 The Fisher-Pitman permutation test when testing for differences in mean and variance. Psychol Rep 94:189-194

22. Jensen MD 2008 Role of body fat distribution and the metabolic complications of obesity. J Clin Endocrinol Metab 93:S57-S63

23. Rasouli N, Molavi B, Elbein SC, Kern PA 2007 Ectopic fat accumulation and metabolic syndrome. Diabetes Obes Metab 9:1-10

24. Vettor R, Milan G, Franzin C, Sanna M, De Coppi P, Rizzuto R, Federspil G 2009 The origin of intermuscular adipose tissue and its pathophysiological implications. Am J Physiol Endocrinol Metab 297:E987-E998

25. Perseghin G, Scifo P, De Cobelli F, Pagliato E, Battezzati A, Arcelloni C, Vanzulli A, Testolin G, Pozza G, Del M, Maschio A, Luzi L 1999 Intramyocellular triglyceride content is a determinant of in vivo insulin resistance in humans: a $1 \mathrm{H}-13 \mathrm{C}$ 
nuclear magnetic resonance spectroscopy assessment in offspring of type 2 diabetic parents. Diabetes 48:1600-1606

26. Snijder MB, Visser M, Dekker JM, Goodpaster BH, Harris TB, Kritchevsky SB, De Rekeneire N, Kanaya AM, Newman AB, Tylavsky FA, Seidell JC 2005 Low subcutaneous thigh fat is a risk factor for unfavourable glucose and lipid levels, independently of high abdominal fat. The Health ABC Study. Diabetologia 48:301-308

27. Iyer A, Fairlie DP, Prins JB, Hammock BD, Brown L 2010 Inflammatory lipid mediators in adipocyte function and obesity. Nat Rev Endocrinol 6:71-82

28. Holmes E, Loo RL, Stamler J, Bictash M, Yap IK, Chan Q, Ebbels T, De Iorio M, Brown IJ, Veselkov KA, Daviglus ML, Kesteloot H, Ueshima H, Zhao L, Nicholson JK, Elliott P 2008 Human metabolic phenotype diversity and its association with diet and blood pressure. Nature 453:396-400
29. Mulder TP, Rietveld AG, van Amelsvoort JM 2005 Consumption of both black tea and green tea results in an increase in the excretion of hippuric acid into urine. Am J Clin Nutr 81:256S-260S

30. Nicholson JK, Holmes E, Wilson ID 2005 Gut microorganisms, mammalian metabolism and personalized health care. Nat Rev Microbiol 3:431-438

31. Calvani R, Miccheli A, Capuani G, Tomassini Miccheli A, Puccetti C, Delfini M, Iaconelli A, Nanni G, Mingrone G 2010 Gut microbiome-derived metabolites characterize a peculiar obese urinary metabotype. Int J Obes (Lond) 34:1095-1098

32. Yamato Y, Kimura A, Inoue T, Kurosawa T, Kato H 2001 Fetal bile acid metabolism: analysis of urinary 3 beta-monohydroxy-delta(5) bile acid in preterm infants. Biol Neonate 80:19-25

33. Lucas A 1991 Programming by early nutrition in man. Ciba Found Symp $156: 38-50$ 